\title{
Synthesis and Characterization of Nano CuO-NiO Mixed Oxides
}

\author{
Abd El-Aziz A.Said*, Mohamed M.Abd El-Wahab, Soliman A. Soliman, Mohamed N. Goda \\ Chemistry Department, Faculty of Science, Assiut University Assiut, Egypt \\ *Corresponding author: aasaid55@yahoo.com
}

Copyright $@ 2014$ Horizon Research Publishing All rights reserved.

\begin{abstract}
A series of single and mixed oxides of nano $\mathrm{CuO}-\mathrm{NiO}$ were prepared by thermal decomposition of the $\mathrm{NiC}_{2} \mathrm{O}_{4} \cdot 2 \mathrm{H}_{2} \mathrm{O}$ and/or $\mathrm{CuC}_{2} \mathrm{O}_{4}$ precursors which obtained via the reaction between alcoholic metal nitrates and oxalic acid solutions. Thermal behavior of the single and mixed salts has been studied using thermal analysis (TG and DTA). Thermal products were characterized using Fouier transform infrared (FTIR), X-ray diffraction (XRD), Electron microscopy (SEM\&TEM), Nitrogen adsorption at $-196^{\circ} \mathrm{C}$ and surface excess oxygen measurements. The results revealed that, pure $\mathrm{NiC}_{2} \mathrm{O}_{4} \cdot 2 \mathrm{H}_{2} \mathrm{O}$ and $\mathrm{CuC}_{2} \mathrm{O}_{4}$ decomposed at 355 and $325^{\circ} \mathrm{C}$, respectively. Also, it was found that the addition of $\mathrm{NiO}$ to $\mathrm{CuO}$ brought a significant increase in the degree of crystallinity of the mixed oxides which is accompanying with an increase in their particle size and a decrease in the surface area. Moreover, addition of $\mathrm{NiO}$ to $\mathrm{CuO}$, also reduces the amount of surface excess oxygen of $\mathrm{CuO}$ due to a synergistic effect.
\end{abstract}

Keywords Mixed Oxides, $\mathrm{CuO}-\mathrm{NiO}, \mathrm{Cu}-\mathrm{Ni}$ oxalates, FTIR, XRD, Nanoparticles, SEM\&TEM

\section{Introduction}

A great deal of fundamental researches has been done on mixed catalysts in the field of heterogeneous catalysis [1-3]. These mixed systems may be more active than their separate components $[4,5]$. The so-called mixed catalysts are often produced by thermal decomposition of the mixed components of their metal salts [6]. It is well known that, nanostructured materials have been extensively explored for the fundamental scientific and technological interests in accessing new classes of functional materials with unprecedented properties and applications [7-9]. Thus a reduction in particle size to nanometer scale results in various interesting properties compared with their bulk properties. Therefore, many methods have been studied to synthesize nanostructured copper oxide [10-16]. $\mathrm{CuO}$ is an important oxide in many chemical processes such as degradation of nitrous oxides, selective catalytic reduction of nitric oxide with ammonia and oxidation of $\mathrm{CO}$, hydrocarbons and fine chemicals [17-19]. Up to date, many studies have been reported about the preparation of $\mathrm{CuO}$ nanomaterials such as nanorods[20], nanowires[21], Shuttke-like structure [22], nanoribbones and nanoparticles[11,16,23-26].

$\mathrm{NiO}$ is a very prosperous material extensively used in catalysis and other applications [27-29]. It is well known that the powder characteristics (particle size, particle size distribution, and shape) are strongly influenced by the preparation process. Thus a variety of strategies have been employed for synthesis nano-sized $\mathrm{NiO}$ [30-36]. In addition pure and doped copper-nickel mixed oxides have been investigated [37-40]. $\mathrm{CuO}-\mathrm{NiO}$ supported $\gamma-\mathrm{Al}_{2} \mathrm{O}_{3}$ was efficiently used in N-Alkylation of ethylenediamine [41] and morphine [42] with alcohols.

It is well known that, the precipitation of oxalates is often used for the elaboration of precursors of high purity and high quality. Whereas preparation of nano crystalline $\mathrm{CuO}-\mathrm{NiO}$ via their oxalate route, to our knowledge, is not reported. So, The present investigation reports the results of an extensive studies on synthesis, structural and surface characterization of nano-crystalline $\mathrm{Cu}-\mathrm{Ni}$ mixed oxide systems by a variety of techniques including thermal analysis (TG \& DTA), Fourier transform infrared (FTIR), x-ray diffraction (XRD), nitrogen adsorption measurements at $-196^{\circ} \mathrm{C}$, surface excess oxygen and electron microscopy (SEM \& TEM),

\section{Experimental}

\subsection{Materials}

Acetone, ethanol and oxalic acid dihydrate were of analytically pure reagent and were used without further purification. Copper nitrate $\mathrm{Cu}\left(\mathrm{NO}_{3}\right)_{2} \cdot 3 \mathrm{H}_{2} \mathrm{O}$ and nickel nitrate $\mathrm{Ni}\left(\mathrm{NO}_{3}\right)_{2} \cdot 6 \mathrm{H}_{2} \mathrm{O}$ were supplied by WINLAB company for laboratory chemicals ( $>99 \%)$, India.

\subsection{Catalysts Preparation}

Pure $\mathrm{Nano} \mathrm{CuO}$ and $\mathrm{NiO}$ were prepared by precipitation 
method as described previously $[35,43]$ with some modifications. In a typical process, analytical grade of copper and nickel nitrates $(0.2 \mathrm{M})$ and $1.0 \mathrm{M}$ oxalic acid were separately dissolved in absolute ethanol at $50^{\circ} \mathrm{C}$. In the course of magnetically stirred of each metal nitrate solution, the same concentration of warm oxalic acid was added as precipitator dropwise with constant stirring in one direction. Kind of light blue sediments were formed, these precipitates were filtered and washed with ethanol and finally washed with small amount of acetone. The washed precipitates were dried in air overnight at room temperature to get the precursors.

$\mathrm{CuO}-\mathrm{NiO}$ mixed oxide systems were prepared by co-precipitation method. The calculated amounts of copper and nickel nitrates were dissolved in ethanol at $50^{\circ} \mathrm{C}$, after stirring the mixtures of metal nitrate solutions; ethanolic oxalic acid solution was added dropwise with constant stirring as described above. The precipitates are then filtered off, washed with ethanol and then with acetone and dried in air overnight at room temperature to obtain the precursors. Pure $\mathrm{CuO}$, Pure $\mathrm{NiO}$ and $\mathrm{CuO}-\mathrm{NiO}$ mixed systems with different ratios of $\mathrm{NiO}(1-50$ wt. \%) were obtained by annealing these precursors at 400 and $600^{\circ} \mathrm{C}$ in muffle furnace under air atmosphere for $3 \mathrm{~h}$.

\subsection{Apparatus and Techniques}

\subsubsection{Thermal Analysis}

Thermogravimetery (TG) and Differential thermal analysis (DTA) were carried out using a computerized Shimadzu Thermal analyzer (TGA 60 Japan) apparatus. The samples were studied under air atmosphere with flowing rate of $30 \mathrm{~mL} \mathrm{~min}^{-1}$. Constant weights of samples $(-5.5 \mathrm{mg}$ ) were used in order to avoid the effect of sample weight on peak shape and temperature. $\alpha-\mathrm{Al}_{2} \mathrm{O}_{3}$ was used as a reference material in this technique. The heating rate was fixed at $10^{\circ} \mathrm{C}$ $\min ^{-1}$.

\subsubsection{Fourier transform infrared (FT-IR)}

FT-IR spectra of the original and the calcined samples at 400 and $600^{\circ} \mathrm{C}$ for $3 \mathrm{~h}$ were recorded in the $4000-400 \mathrm{~cm}^{-1}$ region with a Nicolet (Madison, WI, USA) 710 FT-IR equipped with data station. Dried samples of about $20 \mathrm{mg}$ each were mixed with $100 \mathrm{mg}$ of dry spectral grade $\mathrm{KBr}$ and pressed into disk under hydraulic pressure.

\subsubsection{X-ray diffraction (XRD)}

An $\mathrm{X}$-ray investigation of the individual and mixed solids precalcined at 400 and $600^{\circ} \mathrm{C}$ in air for $3 \mathrm{~h}$ was conducted using a Philips diffractometer (Model PW 2103, $\lambda=1.5418 \mathrm{Ao}, 35 \mathrm{KV}$ and $20 \mathrm{~mA}$ ) with a source of $\mathrm{CuK \alpha} 1$ radiation (Ni Filtered). An on-line data acquisition and handling system facilitated automatic JCPDS library search and match for phase identification purpose.

Crystallite size can be estimated from the full width at half maximum (FWHM) of the X-ray diffraction liner. The broadening of the FWHM is inversely proportional to the average crystallite size (D) as predicted by the well-known Scherer's formula [44] the grain size D is calculated from the following relation:

$$
\mathrm{D}=\frac{K \lambda}{\beta \operatorname{Cos} \theta}
$$

Where $\beta$ is the observed angular width at half maximum intensity of the peak and calculated from:

$$
\beta^{2}=\beta_{\mathrm{s}}^{2}-\beta_{\mathrm{o}}^{2}
$$

where $\beta_{\mathrm{s}}$ is the measured line width at half maximum and $\beta_{\mathrm{o}}$ is the instrumental broadening [45]. $\beta_{\mathrm{o}}=0.16$ with the apparatus used. $\mathrm{K}$ is dimension less number, which is equal to $0.89, \lambda$ is the $\mathrm{X}$-ray wavelength $(1.548 \AA$ for $\mathrm{Cu} \mathrm{K} \alpha 1)$ and $\theta$ is the diffraction angle.

\subsubsection{Nitrogen adsorption}

Nitrogen adsorption- desorption isotherms were measured at $-196^{\circ} \mathrm{C}$ by Quantachrom Instrument Corporation, USA (Model Nova 3200). Test samples were thoroughly out gassed for $2 \mathrm{~h}$ at $250^{\circ} \mathrm{C}$ to a residual pressure of $10^{-4}$ torr and the weight of the out gassed sample was that used in calculations. The porosity of the catalysts was determined from the desorption curve using Nova enhanced data reduction software (Version 2.13). Highly pure nitrogen was used as adsorbent.

\subsubsection{Surface excess oxygen measurement}

The surface excess oxygen was measured by the method described in reference [46]. This method consists in reducing the surface excess oxygen on the oxide catalyst surface with hydrazine and measuring the amount of nitrogen gas evolved with the aid of gasometric technique which early described by Deren et al. [47].

\subsubsection{Electron microscopy (SEM\&TEM)}

The size and morphology of the investigated solids were characterized by Scanning electron microscope (SEM) and Transmittance electron microscop (TEM) JEOL Model JSM-5400 LV (Jeol, Tokyo, Japan). For SEM imaging, the samples were prepared by the gold sputtering technique [69]. Micrographs were obtained in a secondary electron imaging mode using a potential difference of $25 \mathrm{KV}$. Representative sections from the surface were recorded and developed on monochrome paper. For TEM imaging, the sample powder dispersed in ethanol using ultrasonic radiation for $20 \mathrm{~min}$ and a drop of that suspension was place onto the carbon-coated grids. The degree of magnification of TEM images was the same for all the different investigated solids.

\section{Results and Discussion}

\subsection{Thermal Analysis of Pure $\mathrm{CuC}_{2} \mathrm{O}_{4}, \mathrm{NiC}_{2} \mathrm{O}_{4} \cdot 2 \mathrm{H}_{2} \mathrm{O}$ and Their Mixtures}

TG and DTA curves of pure copper oxalate, pure nickel oxalate and their mixtures with different ratios (5-50 wt. \% 
$\mathrm{NiO}$ ) are shown in Fig. (1). TG curve of pure copper oxalate, Fig. (1a), shows one decomposition step in the range of $270-350^{\circ} \mathrm{C}$ with a weight loss of $47.8 \%$. This weight loss is attributed to the decomposition of copper oxalate to copper oxide $(\mathrm{CuO})$ which agrees, approximately, with the theoretical value $(47.52 \%)$. DTA curve shows a sharp exothermic peak maximized at $325^{\circ} \mathrm{C}$ which is again corresponding to the decomposition of copper oxalate to $\mathrm{CuO}$. No other peaks were observed either in TG or DTA on increasing the heating temperature up to $1000^{\circ} \mathrm{C}$ which confirm that the produced $\mathrm{CuO}$ is thermally stable and does not undergo any phase-phase transitions. These results are in agreement with the results obtained by many authors $[16,25$, $26,46]$. From the above results, copper oxalate can decompose to copper oxide according to the following equation [25]:

$$
\mathrm{CuC}_{2} \mathrm{O}_{4}+1 / 2 \mathrm{O}_{2} \quad \mathrm{CuO}+2 \mathrm{CO}_{2}
$$

TG and DTA curves of pure nickel oxalate dihydrate $\mathrm{NiC}_{2} \mathrm{O}_{4} \cdot 2 \mathrm{H}_{2} \mathrm{O}$ are shown in Fig. $(1 \mathrm{~g})$. TG curve exhibits two steps. The first step is in the range of $180-250^{\circ} \mathrm{C}$ with a weight loss of $\sim 19.8 \%$ and is accompanied with an endothermic peak on the DTA curve centered at $233^{\circ} \mathrm{C}$. Such process was attributed to the removal of the two crystalline water molecules to give the anhydrous oxalate form. The weight loss $(19.8 \%)$ in this step is very closely to the theoretical value (19.7\%). The second step in the range of $307-370^{\circ} \mathrm{C}$ exhibits a $39.7 \%$ weight loss and is accompanied with a sharp exothermic peak maximized at $354^{\circ} \mathrm{C}$. This stage may correspond to the decomposition of anhydrous $\mathrm{NiC}_{2} \mathrm{O}_{4}$ to $\mathrm{NiO}[50,51]$. In addition the weight loss $(39.7 \%)$ is in good agreement with the theoretical value $(39.9 \%)$

From the above results, nickel oxalate can thermally decompose to $\mathrm{NiO}$ via the following equations [50].

$$
\begin{array}{lc}
\mathrm{NiC}_{2} \mathrm{O}_{4} \cdot 2 \mathrm{H}_{2} \mathrm{O} & \mathrm{NiC}_{2} \mathrm{O}_{4}+2 \mathrm{H}_{2} \mathrm{O} \\
\mathrm{NiC}_{2} \mathrm{O}_{4}+1 / 2 \mathrm{O}_{2} & \mathrm{NiO}+2 \mathrm{CO}_{2}
\end{array}
$$

TG and DTA curves of $\mathrm{CuC}_{2} \mathrm{O}_{4}$ mixed with $\mathrm{NiC}_{2} \mathrm{O}_{4} \cdot 2 \mathrm{H}_{2} \mathrm{O}$ are shown in Fig.1(b-f). The TG and DTA curves show that the thermal decomposition of these samples to give the corresponding oxides proceeds via two stages. The first one observed in the range of $170-250^{\circ} \mathrm{C}$ with a weight loss of $3.79,8.9,10.4,12.1$ and $17.2 \%$ for the samples $5,10,20,30$ and $50 \mathrm{wt} . \% \mathrm{NiO}$, respectively. The samples are also exhibit endothermic peaks appear on the DTA curves minimized at $\left(168,176,185,193\right.$ and $\left.200^{\circ} \mathrm{C}\right)$ for $\mathrm{NiO}$ loadings of $(5,10$, 20,30 and $50 \mathrm{wt}$. \%) respectively. These peaks attributed to the removal of crystalline water molecules from the samples which originally come from nickel oxalate. The elimination of the crystalline water molecules become more easily as the enhancement observed on the DTA curves as illustrated in the Fig. (1). The second thermal stage occurs in the range of $220-370^{\circ} \mathrm{C}$ with weight loss of $(49.1,45.2,41.3,39.8$ and $37.66 \%)$ is accompanied with exothermic peaks maximized at $\left(320,317\right.$ and $\left.322^{\circ} \mathrm{C}\right)$ for the samples containing 5, 10 and 20 wt. $\% \mathrm{NiO}$, respectively. It is observed that, on increasing the ratio of nickel oxalate above $(20 \mathrm{wt}$. $\% \mathrm{NiO})$, the exothermic peak is splitted into two peaks, the first peak maximized at $\left(317\right.$ and $\left.315^{\circ} \mathrm{C}\right)$ and the second peak maximized at $\left(328\right.$ and $\left.332^{\circ} \mathrm{C}\right)$. These two peaks are attributed to the simultaneous decomposition of copper and nickel oxalates to the corresponding oxides.

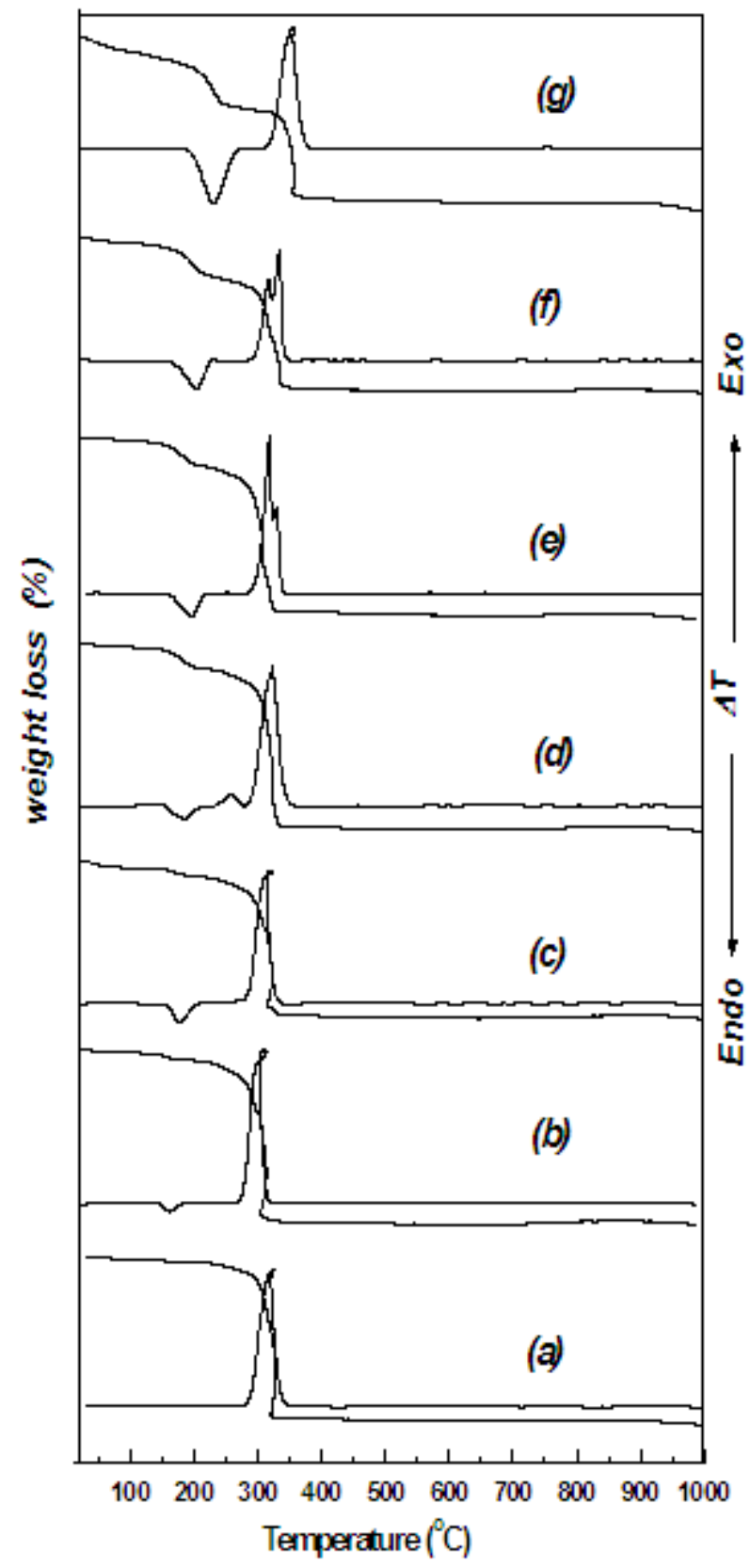

Figure 1. TG and DTA curves of pure copper oxalate (a), pure nickel oxalate $(\mathrm{g})$ and copper mixed with nickel oxalate with corresponding ratios of $\mathrm{NiO} 5 \%$ (b), $10 \%$ (c), $20 \%$ (d), 30\% (e) and 50\% (f).

\subsection{Fourier Transform Infrared (FT-IR)}

Fourier transform infrared (FTIR) analysis of the original and the calcined products of pure copper oxalate, pure nickel oxalate and copper- nickel oxalate mixtures was carried out. Figures (2-4) represent the FTIR spectra obtained for the original and the calcined samples at $400^{\circ}$ and $600^{\circ} \mathrm{C}$ in air for 
$3 \mathrm{~h}$ atmosphere. Spectra of the original samples presented in Fig. (2) displayed bands at 3400-3450, 1628, 1360-1364, $1315,830,760,615-620,530$ and $475-480 \mathrm{~cm}^{-1}$. These bands assigned to

$$
\begin{gathered}
v_{\mathrm{s}}\left(\mathrm{H}_{2} \mathrm{O}\right), v_{\mathrm{as}}(\mathrm{C}=\mathrm{O}), v_{\mathrm{s}}(\mathrm{C}-\mathrm{O})+v(\mathrm{C}-\mathrm{C}), v_{\mathrm{s}}(\mathrm{C}-\mathrm{O})+\delta(\mathrm{O}-\mathrm{C}=\mathrm{O}), \\
v_{\mathrm{s}}(\mathrm{C}-\mathrm{O})+\delta(\mathrm{O}-\mathrm{C}=\mathrm{O}), \delta(\mathrm{O}-\mathrm{C}=\mathrm{O})+v(\mathrm{M}-\mathrm{O}), v(\mathrm{O}-\mathrm{M}-\mathrm{O}), \\
v(\mathrm{M}-\mathrm{O})+v(\mathrm{C}-\mathrm{C}) \text { and } v(\mathrm{M}-\mathrm{O}) \text { respectively, }[35,52] .
\end{gathered}
$$

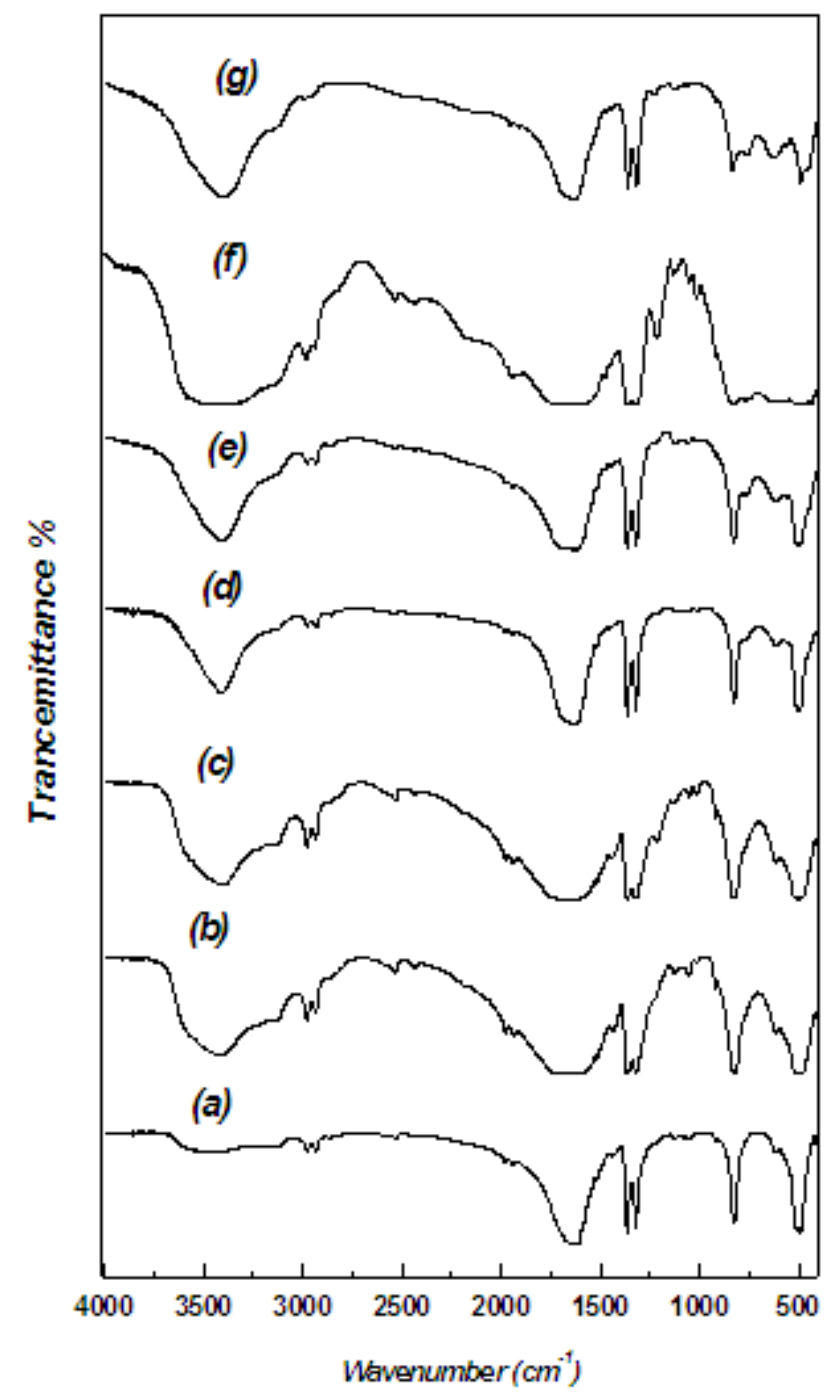

Figure 2. FTIR Spectra of original pure copper oxalate (a), pure nickel oxalate $(\mathrm{g})$ and copper oxalate mixed with nickel oxalate with corresponding ratios of $\mathrm{NiO}$ of $5 \%$ (b), $10 \%$ (c), $20 \%$ (d), 30\% (e) and 50 (f) (wt. \%), as precipitated and dried at $100^{\circ} \mathrm{C}$.

Spectra of pure copper oxalate calcined at 400 and $600^{\circ} \mathrm{C}$ are shown in Figs. (3\&4). The spectra show a broad band at $480-486,530$ and at $580 \mathrm{~cm}^{-1}$. These bands are corresponded to the $\mathrm{Cu}-\mathrm{O}$ bond in the monoclinic structure of $\mathrm{CuO}$ [53] The weak bands in the region of $700-1000 \mathrm{~cm}^{-1}$ appeared especially in the samples calcined at $400^{\circ} \mathrm{C}$, may be attributed to the different vibrations modes of $\mathrm{CO}_{3}{ }^{2-}$. The $\mathrm{CO}_{3}{ }^{2-}$ anions are formed due to the exposure of the samples to ambient after calcination and adsorption of $\mathrm{CO}_{2}[54,55]$ to form $\mathrm{CO}_{3}{ }^{2-}$. The band which appeared at the range $\left(1050-1110 \mathrm{~cm}^{-1}\right)$ may be attributed to the chemisorptions of $\mathrm{O}^{2-}$ on the surface of the catalysts [56].

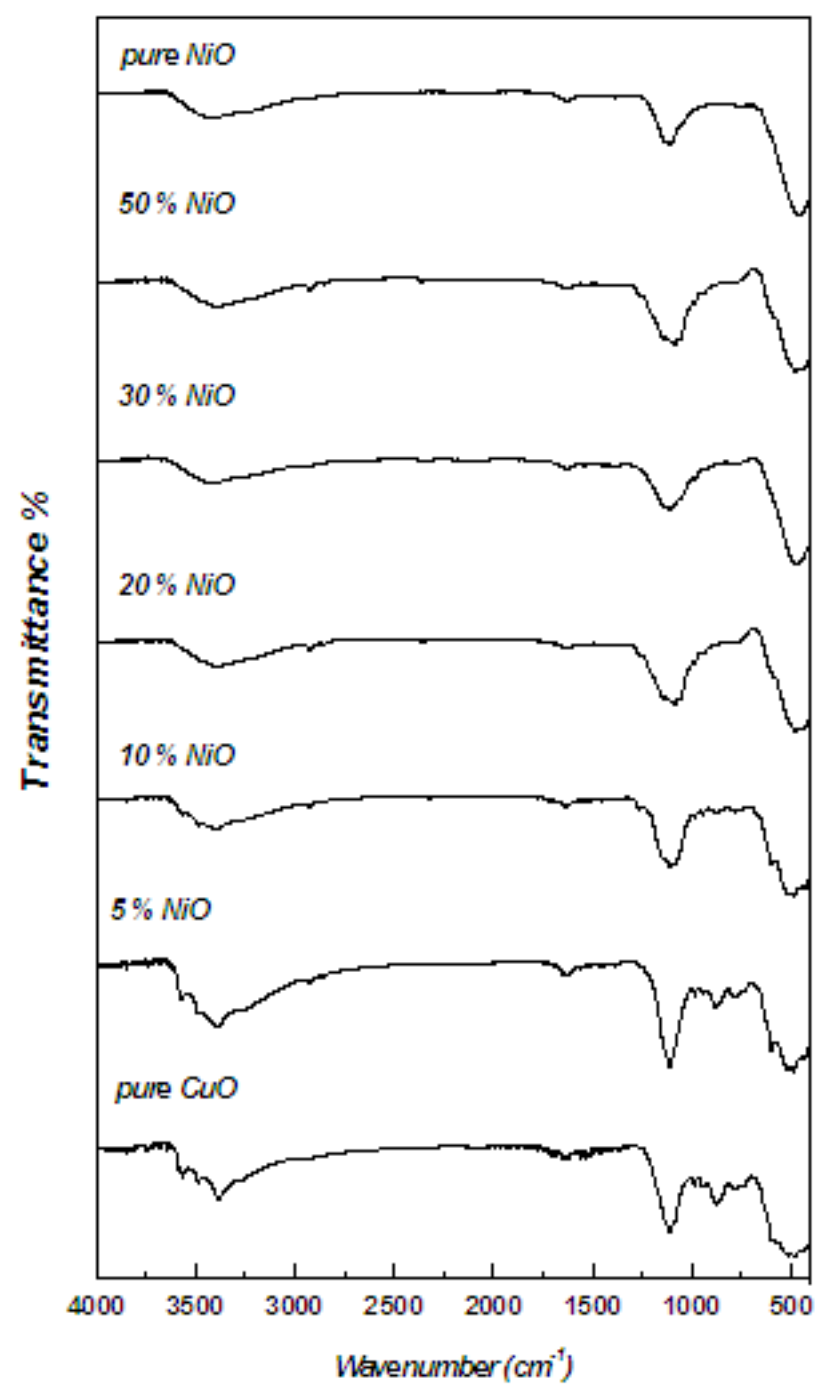

Figure 3. FTIR Spectra of pure $\mathrm{CuO}$, pure $\mathrm{NiO}$ and $\mathrm{CuO}-\mathrm{NiO}$ mixed oxide systems calcined at $400^{\circ} \mathrm{C}$ in air atmosphere for $3 \mathrm{~h}$.

The FTIR spectra of pure nickel oxalate calcined at 400 and $600^{\circ} \mathrm{C}$ are shown in Figs. (3\&4). The spectra show a broad band exists in the range of $440-470 \mathrm{~cm}^{-1}$, this band is assigned to the Ni-O bond stretching vibrations [57-59]. The broadness of the absorption band indicates that $\mathrm{NiO}$ powder is nanocrystalline $[51,60]$. The other bands present in the spectra which assigned at the same wave number are explained in the $\mathrm{CuO}$ spectra.

The spectra of $\mathrm{CuO}$ mixed with $\mathrm{NiO}$ and calcined at 400 and $600^{\circ} \mathrm{C}$ indicate that no bands are assigned corresponding to the formation of new spinel. The observed broad band assigned at $440-530 \mathrm{~cm}^{-1}$ of the mixed oxides may be attributed to the $\mathrm{M}-\mathrm{O}$ vibration. In addition, this broadness is a proof of the existence of nano-particles exists in the mixed system [60]. The broad band assigned at $3200-3500 \mathrm{~cm}^{-1}$ in all samples may be attributed to vibration of physically adsorbed water. This band is completely different from coordinated water in compounds [51]. The other band which 
appeared at $1635 \mathrm{~cm}^{-1}$ is due to the bending vibration of $\mathrm{H}_{2} \mathrm{O}$. This means that the plain band at $3200-3500 \mathrm{~cm}^{-1}$ and the sharp band at $1635-1640 \mathrm{~cm}^{-1}$ assigned to the stretching and bending vibration of $\mathrm{OH}$ group of $\mathrm{H}_{2} \mathrm{O}$ [61].

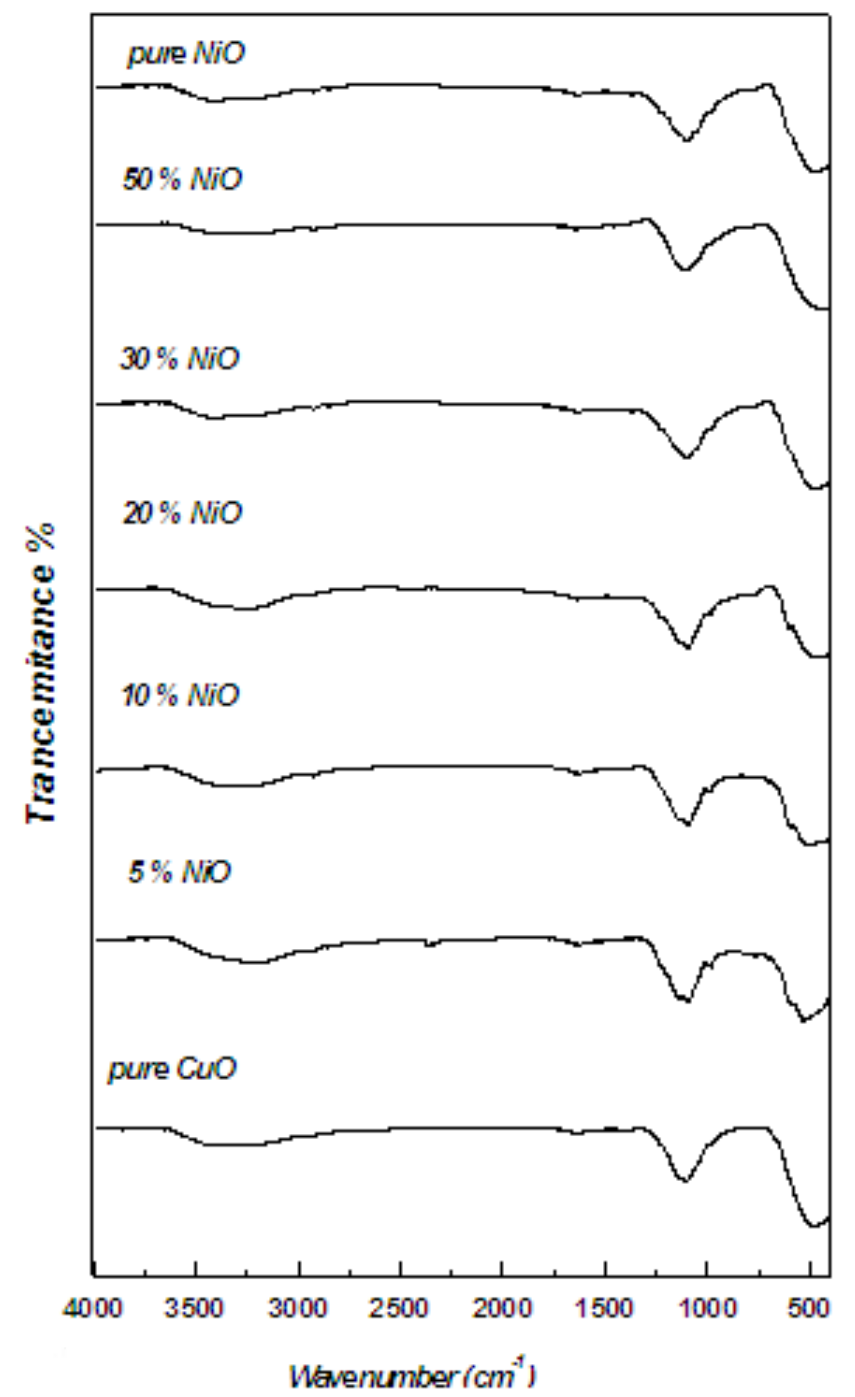

Figure 4. FTIR Spectra of pure $\mathrm{CuO}$, pure $\mathrm{NiO}$ and $\mathrm{CuO}-\mathrm{NiO}$ mixed oxide systems calcined at $600{ }^{\circ} \mathrm{C}$ in air atmosphere for $3 \mathrm{~h}$.

\subsection{X-Ray Diffraction (XRD)}

The x-ray diffraction patterns (XRD) obtained for the parent materials, pure copper oxalate $\left(\mathrm{CuC}_{2} \mathrm{O}_{4}\right)$ and nickel oxalate $\left(\mathrm{NiC}_{2} \mathrm{O}_{4} \cdot 2 \mathrm{H}_{2} \mathrm{O}\right)$, are graphically represented in Figs. (5). Matching the XRD patterns of copper oxalate with the reported data in the (JCPDS No. 00-021-0297), results show that the prepared sample is well crystalline and the predominate diffraction lines correspond to $\mathrm{CuC}_{2} \mathrm{O}_{4}$ lattice are at $\mathrm{d}(\AA)=3.896,2.484,2.32,2.139,1.946$ and 1.773 . On the other hand, matching the XRD patterns of nickel oxalate with that identified in the (JCPDS No. 01-073-2580) show also that the synthesized sample is well crystalline and the diffraction lines correspond to $\mathrm{NiC}_{2} \mathrm{O}_{4} \cdot 2 \mathrm{H}_{2} \mathrm{O}$ lattice are at $\mathrm{d}$ $(\AA)=4.727,3.914,2.957,2.523,2.064$ and 1.865 .
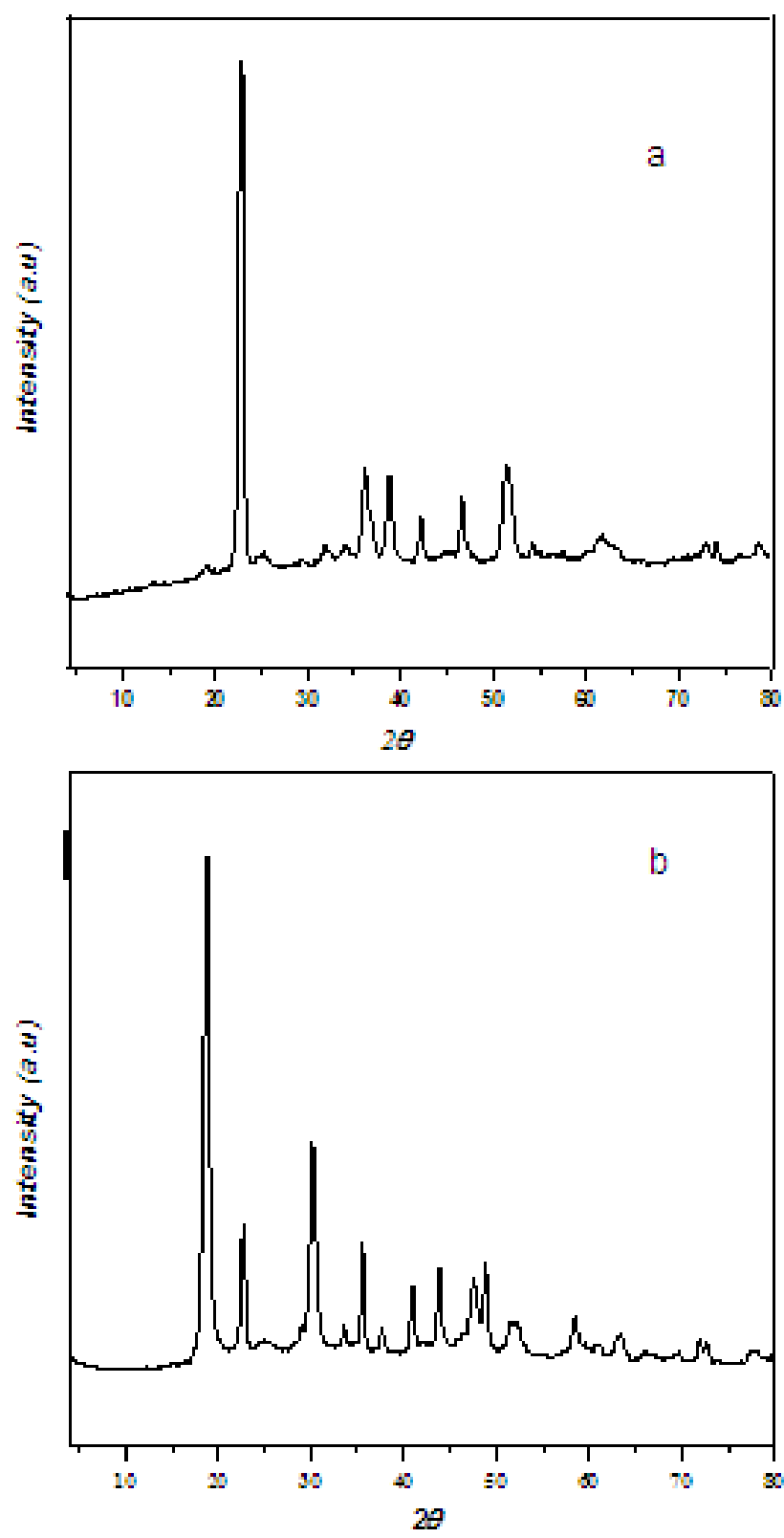

Figure 5. X-ray patterns of the as-synthesized copper oxalate $\left(\mathrm{CuC}_{2} \mathrm{O}_{4}\right)(a)$ and nickel oxalate $\left(\mathrm{NiC}_{2} \mathrm{O}_{4} \cdot 2 \mathrm{H}_{2} \mathrm{O}\right)(\mathrm{b})$.

These results are in good agreement with the results previously obtained $[25,35,43,49]$.

The XRD diffractogrames of pure copper oxide, pure nickel oxide and their mixtures containing 10,20,30 and 50 wt. \% $\mathrm{NiO}$ calcined at 400 and $600^{\circ} \mathrm{C}$ were graphically represented in Figs. (6\&7). From these figures, matching the XRD patterns of pure copper oxalate calcined at 400 and $600^{\circ} \mathrm{C}$ with that identified in the (JCPDS No. 04-012-7238), results show that the predominant diffraction lines correspond to $\mathrm{CuO}$ lattice are at $\mathrm{d}(\AA)=2.753,2.75,2.527$, $2.323,1.867,1.408$ and 1.265 . The XRD patterns of pure nickel oxalate calcined at 400 and $600^{\circ} \mathrm{C}$ were matched with the (JCPDS No.04-012-6347) and the results show that the diffraction lines correspond to $\mathrm{NiO}$ lattice are at $\mathrm{d}(\AA)=$ $2.413,2.089,1.477,1.259$ and 1.206 . 


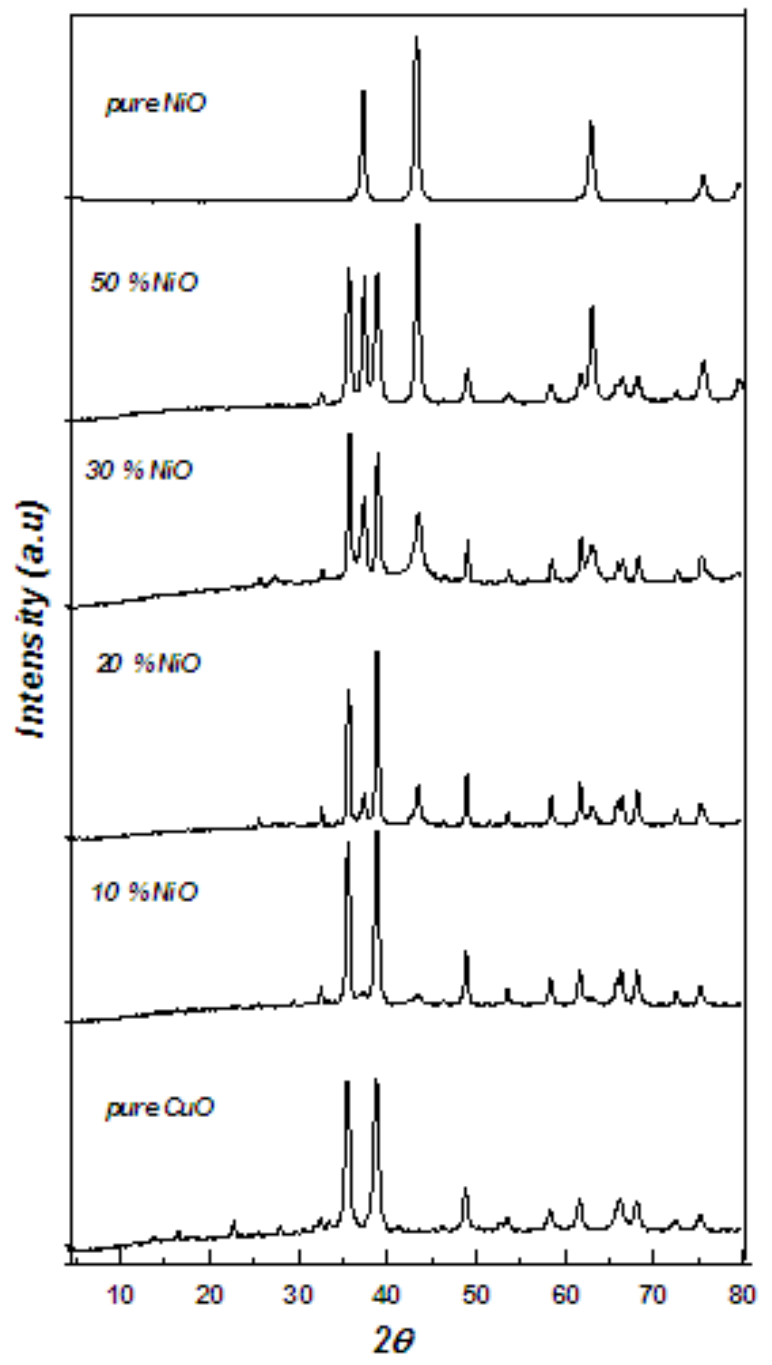

Figure 6. X-ray diffractograms of pure $\mathrm{CuO}$, pure $\mathrm{NiO}$ and $\mathrm{CuO}-\mathrm{NiO}$ mixed systems (wt. \%) calcined at $400^{\circ} \mathrm{C}$ in air atmosphere for $3 \mathrm{~h}$.

The diffraction patterns for the copper-nickel oxalate mixtures calcined at $400,500,600$ and $700^{\circ} \mathrm{C}$ were matched with that identified in the JCPDS cards. The results show that at lower $\mathrm{NiO}$ mixing ratio (up to $10 \mathrm{wt}$. \% $\mathrm{NiO}$ ) the predominant diffraction lines are corresponding to $\mathrm{CuO}$.

Above $10 \mathrm{wt}$. \% NiO, the lines corresponding to $\mathrm{NiO}$ start to appear and their intensities increase with increasing the percentage content of $\mathrm{NiO}$ up to $50 \%$. Examination of these patterns illustrate that no new peaks corresponding to the solid-solid interactions were observed between the thermally produced $\mathrm{NiO}$ and $\mathrm{CuO}$. These results are in good agreement with those obtained from thermal analysis DTA Fig. (1), which shows that, no peaks observed due to the solid-solid interaction between $\mathrm{CuO}$ and $\mathrm{NiO}$. The crystallite size of crystalline phases present in the different investigated samples was calculated from the line broadening of the main diffraction lines of these phases using Scherrer equation [44].

The diffraction peaks at $2 \theta$ values of $35.55,38.66$ and 48.84o corresponding to (-1 111$),\left(\begin{array}{lll}1 & 1 & 1\end{array}\right)$ and (-2 $\left.0 \begin{array}{ll}0 & 2\end{array}\right)$ Miller planes were selected for calculating the crystallite size for
$\mathrm{CuO}$ phase. On the other hand, the diffraction peaks at $2 \theta$ values of $37.28,43.32$ and $62.9^{\circ}$ corresponding to (llll 11 , , (2 $00)$ and (2 20 ) Miller planes were selected for calculating the crystallite size for $\mathrm{NiO}$ phase as these peaks are well isolated and with high intensity. The average of these measurements was reported as crystallite size for each phase. The crystallite sizes for $\mathrm{CuO}$ and $\mathrm{NiO}$ phases for the samples calcined at 400 and $600^{\circ} \mathrm{C}$ are cited in Tables 1 . It is clear that, mixing of $\mathrm{CuO}$ with different ratios of $\mathrm{NiO}$ followed by calcination at 400 and $600^{\circ} \mathrm{C}$ led to a significant increase in the crystallite size of $\mathrm{CuO}$ and $\mathrm{NiO}$ phases. Moreover, the observed increase in the value of the crystallite size of $\mathrm{NiO}$ upon loaded to the $\mathrm{CuO}$ surface may be attributed to the agglomeration of $\mathrm{NiO}$ particles.

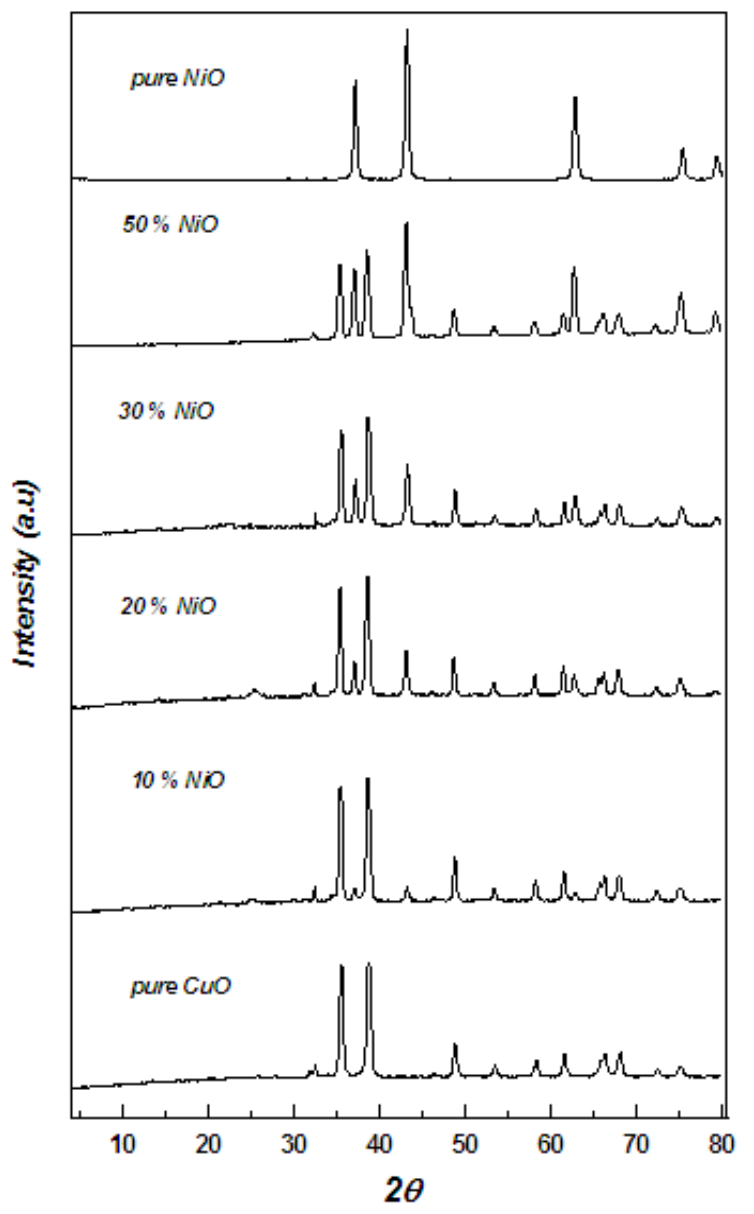

Figure 7. X-ray diffractograms of pure $\mathrm{CuO}$, pure $\mathrm{NiO}$ and $\mathrm{CuO}-\mathrm{NiO}$ mixed systems (wt.\%) calcined at $600{ }^{\circ} \mathrm{C}$ in air atmosphere for $3 \mathrm{~h}$.

It is important to mention here that, the effective increase in crystallite sizes of both $\mathrm{NiO}$ and $\mathrm{CuO}$ could be attributed to conversion of some $\mathrm{NiO}$ to $\mathrm{Ni}_{2} \mathrm{O}_{3}$ and also some $\mathrm{CuO}$ to $\mathrm{Cu}_{2} \mathrm{O}$ phases via a synergistic mechanism [37, 62-64] between the nickel and copper oxides as follows:

$$
\begin{array}{cc}
2 \mathrm{CuO} & \mathrm{Cu}_{2} \mathrm{O}+1 / 2 \mathrm{O}_{2} \\
2 \mathrm{NiO}+1 / 2 \mathrm{O}_{2} & \mathrm{Ni}_{2} \mathrm{O}_{3} \\
2 \mathrm{CuO}+2 \mathrm{NiO} & \mathrm{Cu}_{2} \mathrm{O}+\mathrm{Ni}_{2} \mathrm{O}_{3}
\end{array}
$$

It is important to mention here from the above equations 
that the synergestic effect leads to the existence of $\mathrm{Cu}^{+}$and $\mathrm{Ni}^{3+}$ in the host oxides together with $\mathrm{Cu}^{2+}$ and $\mathrm{Ni}^{3+}$. The presence of dual in the oxide mixyures valances should modify their textural, morphological, electrical and catalytic properties.

Table 1. Variation of crystallite sizes of $\mathrm{CuO}$ and $\mathrm{NiO}$ phases in the investigated solids calcined at 400 and $600^{\circ} \mathrm{C}$.

\begin{tabular}{|c|c|c|c|c|}
\hline \multirow{2}{*}{ Catalyst } & \multicolumn{2}{|c|}{$400{ }^{\circ} \mathrm{C}$} & \multicolumn{2}{c|}{$600{ }^{\circ} \mathrm{C}$} \\
\cline { 2 - 5 } & $\begin{array}{c}\mathrm{D}_{\mathrm{CuO}} \\
(\mathrm{nm})\end{array}$ & $\mathrm{D}_{\mathrm{NiO}}(\mathrm{nm})$ & $\mathrm{D}_{\mathrm{CuO}}(\mathrm{nm})$ & $\begin{array}{c}\mathrm{D}_{\mathrm{NiO}} \\
(\mathrm{nm})\end{array}$ \\
\hline Pure $\mathrm{CuO}$ & 12.6 & - & 18.9 & - \\
\hline $10 \% \mathrm{NiO}$ & 16.2 & 4.1 & 22.8 & 11.1 \\
\hline $20 \% \mathrm{NiO}$ & 20.0 & 8.7 & 26.7 & 14.4 \\
\hline $30 \% \mathrm{NiO}$ & 22.5 & 11.5 & 29.6 & 17.5 \\
\hline $50 \% \mathrm{NiO}$ & 23.6 & 15.5 & 30.2 & 20.1 \\
\hline $\mathrm{Pure} \mathrm{NiO}$ & - & 18.6 & - & 24.3 \\
\hline
\end{tabular}

\subsection{Nitrogen Adsorption}

The adsorption-desorption isotherms of nitrogen gas at liquid nitrogen temperature $\left(-196^{\circ} \mathrm{C}\right)$ were measured for pure $\mathrm{CuO}, \mathrm{NiO}$ and their mixtures calcined at 400 and $600^{\circ} \mathrm{C}$.

All isotherms (not given) of pure and mixed calcined samples are of type II of Brunauer's classification [65]. In addition, the adsorbents under investigation are characterized by being irreversible and exhibit hysteresis loop close in the low relative pressure range. The hysteresis loop belongs to type $\mathrm{H} 4$ with little of type $\mathrm{E}$ of de Bore classification [66]. The specific surface area $S_{B E T}$ was obtained by applying the BET equation in its normal range of applicability $\left(\mathrm{p} / \mathrm{p}^{\mathrm{o}}=0.05-0.35\right)$ with cross-sectional area of $\mathrm{N}_{2}=16.2 \AA^{2}$. Another series of specific surface area $\mathrm{S}_{\mathrm{t}}$ was calculated from the $\mathrm{V}_{\mathrm{a}-\mathrm{t}}$ plots. These plots were constructed using standard t-curves depending on the magnitudes of C-constant in the BET-equation (second column of Tables (2\&3)). The computed $\mathrm{S}_{\mathrm{BET}}$ values of pure and mixed oxide samples calcined at 400 and $600{ }^{\circ} \mathrm{C}$ are cited in Table $(2,3)$. Examination of Tables (2\&3), the following conclusions can be drawn:

i. At all calcination temperatures, pure $\mathrm{CuO}$ possesses the highest value of $\mathrm{S}_{\mathrm{BET}}$ compared to pure $\mathrm{NiO}$. The $\mathrm{S}_{\mathrm{BET}}$ value of pure $\mathrm{CuO}$ due to mixing with $\mathrm{NiO}$ was found to suffer a progressive decrease to an extent that proportional to the amount of $\mathrm{NiO}$ added up to $50 \mathrm{wt}$.. The decrease was, however, more pronounced with the low ratios of $\mathrm{NiO}$ (1-10 wt. \%). The $\mathrm{S}_{\mathrm{BET}}$ value decreased from 25.5 to $13.9 \mathrm{~m}^{2} \mathrm{~g}^{-1}$ on doping of $\mathrm{CuO}$ with 5 wt. $\% \mathrm{NiO}$ for the solids calcined at $400^{\circ} \mathrm{C}$. This reflects that about $45.5 \%$ reduction in the $\mathrm{S}_{\mathrm{BET}}$ value of pure $\mathrm{CuO}$ occurred. Further increase in $\mathrm{NiO}$ ratio up to $10 \mathrm{wt}$ \% causes a reduction in the $\mathrm{S}_{\mathrm{BET}}$ value of pure $\mathrm{CuO}$ from 25.5 to $7.8 \mathrm{~m}^{2} \mathrm{~g}^{-1}$ which is equal to $69.4 \%$. Above these ratios, the $\mathrm{S}_{\mathrm{BET}}$ values are steadily decreased with increasing the amount of $\mathrm{NiO}$ added up to $50 \%$. This decrease in the $\mathrm{S}_{\mathrm{BET}}$ value might be discussed in terms of (i) the lower value of $\mathrm{S}_{\mathrm{BET}}$ of $\mathrm{NiO}$ added which consequently reduces the surface area of the $\mathrm{CuO}$, (ii) the continuous decrease in the total pore volume with the increase in the $\mathrm{NiO}$ content and (iii) blocking of some pores of the host oxide by $\mathrm{NiO}$ additions. This blocking may be attributed to the cationic substitution of $\mathrm{CuO}$ by $\mathrm{NiO}$. Furthermore, the decrease in $\mathrm{S}_{\mathrm{BET}}$ due to $\mathrm{NiO}$ additions can be discussed in terms of the particle size. In fact, X-ray analysis of the samples calcined at different temperatures indicated a significant increase in the particle size of the solids by mixing with $\mathrm{NiO}$. This increase in the particle size of the calcined samples should be accompanied by a significant decrease in the surface areas of the mixed solids.

ii. Raising the calcination temperatures from 400 to $600^{\circ} \mathrm{C}$, resulted in a significant and contineous decrease in the $\mathrm{S}_{\mathrm{BET}}$ values of pure and mixed oxides. This behavior may be attributed to the high temperature sintering process.

iii. The values of $\mathrm{S}_{\mathrm{BET}}$ and $\mathrm{S}_{\mathrm{t}}$ are close to each other which justify the correct choice of t-curve for analysis and indicate the absence of ultramicropores.

Table 2. Texture data of the $\mathrm{CuO}-\mathrm{NiO}$ mixed oxide systems (wt./wt.) calcined at $400^{\circ} \mathrm{C}$ in air for $3 \mathrm{~h}$.

\begin{tabular}{|c|c|c|c|c|c|}
\hline Mixing & $\mathrm{S}_{\mathrm{BET}}$ & $\mathrm{S}_{\mathrm{t}}$ & Total pore volume & Average pore diameter & $\mathrm{S}_{\mathrm{t}} / \mathrm{S}_{\text {BET }}$ \\
\hline$(\%)$ & $\left(\mathrm{m}^{2} \mathrm{~g}^{-1}\right)$ & $\left(\mathrm{m}^{2} \mathrm{~g}^{-1}\right)$ & $\left(\mathrm{cc} \mathrm{g}^{-1}\right)$ & $4)$ & $(\%)$ \\
\hline $\mathrm{Pure} \mathrm{CuO}$ & 25.5 & 25.5 & 0.0309 & 48.5 & 900 \\
\hline $1 \% \mathrm{NiO}$ & 22.7 & 22.6 & 0.02688 & 57.3 & 99.5 \\
\hline $3 \% \mathrm{NiO}$ & 18.6 & 18.5 & 0.02336 & 44.8 & 98.6 \\
\hline $5 \% \mathrm{NiO}$ & 13.9 & 13.7 & 0.0156 & 52.9 & 99.3 \\
\hline $7 \% \mathrm{NiO}$ & 11.2 & 11.1 & 0.01461 & 69.6 & 98.6 \\
\hline $10 \% \mathrm{NiO}$ & 7.8 & 7.7 & 0.01185 & 53.3 & 97.9 \\
\hline $20 \% \mathrm{NiO}$ & 5.6 & 5.5 & 0.00832 & 57 & 99.1 \\
\hline $30 \% \mathrm{NiO}$ & 4.3 & 4.3 & 0.00476 & 55.2 & 98.3 \\
\hline $40 \% \mathrm{NiO}$ & 3.6 & 3.5 & 0.00355 & 81.8 & 98.6 \\
\hline $50 \% \mathrm{NiO}$ & 3.5 & 3.4 & 0.00502 & 52 & 99.1 \\
\hline $\mathrm{Pure} \mathrm{NiO}$ & 12.4 & 12.2 & 0.01606 & & \\
\hline
\end{tabular}


Table 3. Texture data of the CuO-NiO mixed oxide systems (wt./wt.) calcined at $600{ }^{\circ} \mathrm{C}$ in air for $3 \mathrm{~h}$.

\begin{tabular}{|c|c|c|c|c|c|}
\hline Mixing & $\mathrm{S}_{\mathrm{BET}}$ & $\mathrm{S}_{\mathrm{t}}$ & Total pore Volume & Average pore diameter & $\mathrm{S}_{\mathrm{t}} / \mathrm{S}_{\mathrm{BET}}$ \\
\hline$(\%)$ & $\left(\mathrm{m}^{2} \mathrm{~g}^{-1}\right)$ & $\left(\mathrm{m}^{2} \mathrm{~g}^{-1}\right)$ & $\left(\mathrm{cc} \mathrm{g}^{-1}\right)$ & 45.2 & 99.7 \\
\hline $\mathrm{Pure} \mathrm{CuO}$ & 15.6 & 15.5 & 0.00968 & 35.9 & 99.9 \\
\hline $1 \% \mathrm{NiO}$ & 12.6 & 12.5 & 0.00678 & 55.1 & 99.9 \\
\hline $3 \% \mathrm{NiO}$ & 9.2 & 9.2 & 0.00622 & 46.9 & 98.4 \\
\hline $5 \% \mathrm{NiO}$ & 6.5 & 6.4 & 0.00525 & 58.8 & 98.1 \\
\hline $7 \% \mathrm{NiO}$ & 5.4 & 5.3 & 0.00649 & 56.1 & 99.7 \\
\hline $10 \% \mathrm{NiO}$ & 3.7 & 3.6 & 0.00513 & 50.8 & 99.6 \\
\hline $20 \% \mathrm{NiO}$ & 2.6 & 2.6 & 0.00418 & 59.2 & 99.6 \\
\hline $30 \% \mathrm{NiO}$ & 2.3 & 2.3 & 0.0038 & 68.2 & 98.6 \\
\hline $40 \% \mathrm{NiO}$ & 2.1 & 2.1 & 0.0035 & 65 & 98.3 \\
\hline $50 \% \mathrm{NiO}$ & 1.8 & 1.8 & 0.00293 & 45 & 99.1 \\
\hline $\mathrm{Pure} \mathrm{NiO}$ & 5.4 & 5.3 & 0.00608 & & \\
\hline
\end{tabular}

\subsection{Determination of Surface Excess Oxygen}

The results of experiments carried out for determining the amount of surface excess oxygen for pure $\mathrm{CuO}$, pure $\mathrm{NiO}$ and $\mathrm{CuO}-\mathrm{NiO}$ mixed oxide systems calcined at 400 and $600^{\circ} \mathrm{C}$ are cited in Table (4).

Table 4. Concentration of surface excess oxygen $\left(\mathrm{mg} \mathrm{g}^{-1}\right)$ for $\mathrm{CuO}-\mathrm{NiO}$ mixed oxide systems calcined at 400 and $600^{\circ} \mathrm{C}$.

\begin{tabular}{|c|c|c|}
\hline \multirow{2}{*}{ Catalyst } & \multicolumn{2}{|c|}{ Surface excess oxygen $\left(\mathrm{mg} \mathrm{g}^{-1}\right)$} \\
\cline { 2 - 3 } & $400{ }^{\circ} \mathrm{C}$ & $600{ }^{\circ} \mathrm{C}$ \\
\hline Pure $\mathrm{CuO}$ & 17.5 & 14.9 \\
\hline $1 \% \mathrm{NiO}$ & 16.2 & 14.0 \\
\hline $3 \% \mathrm{NiO}$ & 15.1 & 12.7 \\
\hline $5 \% \mathrm{NiO}$ & 14.1 & 11.1 \\
\hline $7 \% \mathrm{NiO}$ & 12.5 & 9.6 \\
\hline $10 \% \mathrm{NiO}$ & 11.1 & 8.6 \\
\hline $20 \% \mathrm{NiO}$ & 7.2 & 4.9 \\
\hline $30 \% \mathrm{NiO}$ & 5.7 & 3.6 \\
\hline $40 \% \mathrm{NiO}$ & 4.7 & 2.6 \\
\hline $50 \% \mathrm{NiO}$ & 3.4 & 1.9 \\
\hline $\mathrm{Pure} \mathrm{NiO}$ & 3.2 & 1.4 \\
\hline
\end{tabular}

Examination of the results in Table (4) shows the following observations:

i. Pure $\mathrm{CuO}$ possesses the highest value of surface excess oxygen than pure $\mathrm{NiO}$ at all calcination temperatures.

ii. The amount of surface excess oxygen of pure $\mathrm{CuO}$ was found to suffer a progressive decrease with the additions of $\mathrm{NiO}$ at different calcination temperatures. The decrease was found, however, more pronounced for the lower additions (1-10 wt. \%) and extended up to 20 wt. $\% \mathrm{NiO}$. Above this ratio, the amount of surface excess oxygen was steadly decreased with the additions of $\mathrm{NiO}$ up to $50 \mathrm{wt}$ \% $\mathrm{NiO}$. The additions of
$7,10,20,30,40$ and 50 wt. $\% \mathrm{NiO}$ were found to reduce the amount of surface excess oxygen by 28.5 , $36.5,58.567,72.8$, and $80.7 \%$, respectively, for the catalysts calcined at $400^{\circ} \mathrm{C}$.

iii. Raising the calcination temperatures from 500 to $700^{\circ} \mathrm{C}$, resulted in a significant decrease in the amount of surface excess oxygen for the pure $\mathrm{CuO}$ and mixed oxide systems.

However, it is well known that, $\mathrm{CuO}$ is a nonstoichiometric and p-type semiconductor. According to Jeong and Choi [67], $\mathrm{CuO}$ was confirmed to be a metal deficient $\mathrm{p}$-type semiconductor with copper vacancies at low temperatures. On the other hand, adsorption of oxygen and change in electrical conductivity of $\mathrm{NiO}[68,69-71]$ have shown that, at room temperature, chemisorption of oxygen occurs in the form of negatively charged species. As regards with the nature of negatively charged adsorbed species, the formation of $\mathrm{O}_{2}^{-}, \mathrm{O}^{-}, \mathrm{O}^{2-}$ ions has been postulated [68].

It is worth mentioning that, the formation of charged chemisorbed oxygen species is accompanied by the promotion of an appropriate number of cations in the oxide crystal lattice to a higher oxidation state. In the case of $\mathrm{NiO}$, this will be the oxidation of $\mathrm{Ni}^{2+}$ to $\mathrm{Ni}^{3+}$ [68], which from the viewpoint of the semiconducting properties of the oxides is equivalent to the formation of positive holes [72]. Therefore, the oxidation power of nonstoichiometric $\mathrm{NiO}$ can be plausibly ascribed to the creation of surface $\mathrm{Ni}^{3+}$. The formation of chemisorbed $\mathrm{O}^{-}$species on $\mathrm{NiO}$ has been reported [68] to take place at $150-250^{\circ} \mathrm{C}$, at $250^{\circ} \mathrm{C}$ chemisorbed oxygen species was found to predominant as $\mathrm{O}^{2-}$.

For $\mathrm{CuO}-\mathrm{NiO}$ mixed oxide systems, a synergism [73,62-64] between the two oxides will be occurred. As a result of the syngestic effect,the decrease in the amount of excess oxygen may be attributed to the synergistic effect. The above equations $(4 \& 5)$ revealed that the addition of $\mathrm{NiO}$ to $\mathrm{CuO}$ is accompanied with consumption of oxygen released from $\mathrm{CuO}$. Moreover, the observed decrease in the 
specific surface area on mixing $\mathrm{CuO}$ with $\mathrm{NiO}$ may correspond to such decrease in the surface excess oxygen. The fact that the changes in the values of surface excess oxygen ran almost parallel to the values of specific surface areas of the various adsorbents. This parallelism might suggest the idea that oxygen is uptaken on top of surface layers of the investigated adsorbents [37,73].

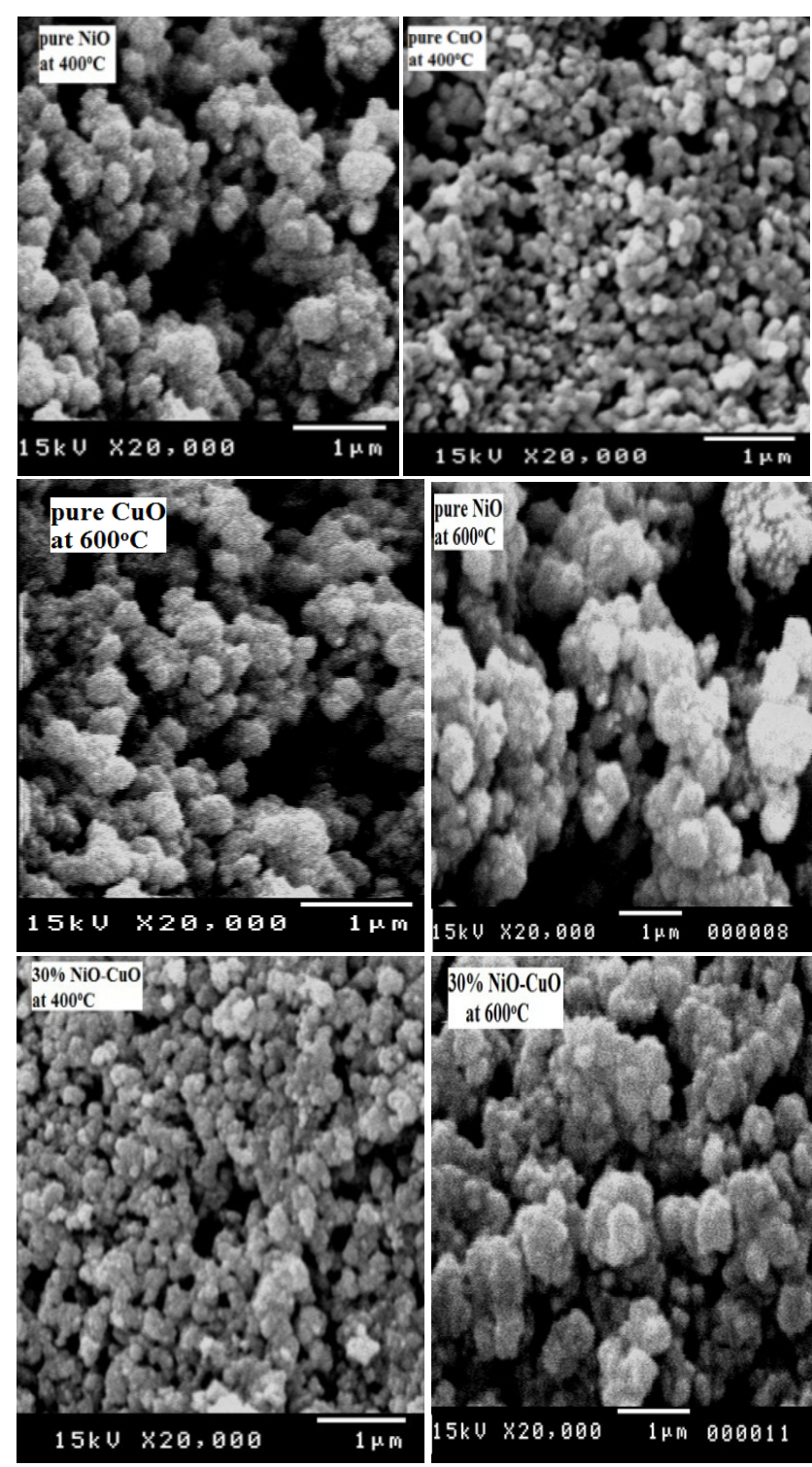

Figure 8. SEM photographs of $\mathrm{CuO}-\mathrm{NiO}$ mixed oxide nanoparticles.

\subsection{Electron Microscopy (SEM\&TEM)}

The surface morphological study of the pure $\mathrm{CuO}$, pure $\mathrm{NiO}$ and $\mathrm{CuO}$ mixed with 30 wt.\% of $\mathrm{NiO}$ catalysts nano-particles calcined at 400 and $600^{\circ} \mathrm{C}$ was carried out using SEM and TEM and the images are shown in Figs. (8\&9). Fig. (8) shows the SEM images of the solidss under investigation. From the SEM analysis, one can conclude the formation of aggregates of semi-spherical structure with almost uniform distribution. Inspection of these images revealed that: i. At all calcination temperatures, Pure $\mathrm{CuO}$ catalyst has small aggregates size compared to that of pure $\mathrm{NiO}$ and 30 wt. \% NiO-CuO solids.

ii. The aggregates size increases with increasing the addition of $\mathrm{NiO}$.

iii. The aggregates size increases on increasing the calcination temperature from 400 to $600^{\circ} \mathrm{C}$, this agglomeration resulted in an increase of the crystallite size of the particles.

The transmittance electron microscopic (TEM) photographs of the solids have been given in Fig. (9). The size of nano-particles obtained from TEM images show sizes of 12-20 nm for the pure $\mathrm{CuO}$ and $\mathrm{NiO}$ catalysts and 25-40 $\mathrm{nm}$ for the mixed oxides ( $30 \mathrm{wt} . \% \mathrm{NiO}$ ) calcined at 400 and $600^{\circ} \mathrm{C}$, respectively. These results are in a close agreement with the results that obtained from the XRD diffraction pattern see Table (1).

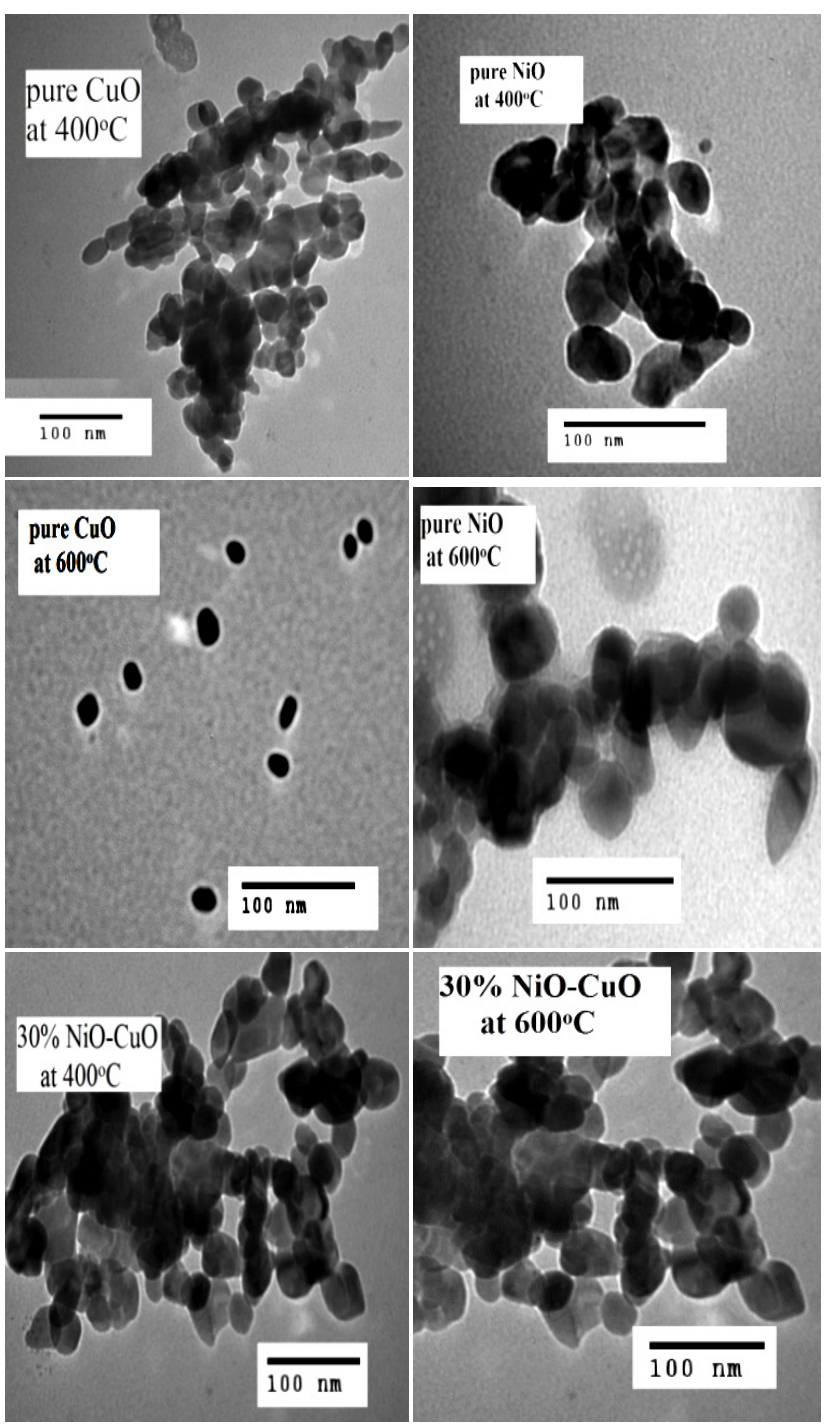

Figure 9. TEM photographs $\mathrm{CuO}-\mathrm{NiO}$ mixed oxides nanoparticles

\section{Conclusion}


The main conclusions derived from the results obtained can be summarized as follows:

1. Pure and mixed solids of nano $\mathrm{CuO}$ and $\mathrm{NiO}$ have been synthesized via oxalic acid rout.

2. $\mathrm{CuO}, \mathrm{NiO}$ and their mixtures are thermally stable on No solid-solid interaction was detected between the $\mathrm{NiO}$ and $\mathrm{CuO}$ oxides.

3. The addition of $\mathrm{NiO}$ to $\mathrm{CuO}$ resulted in increasing the particle size and decreasing the surface area and surface excess oxygen over the investigated solids.

\section{REFERENCES}

[1] W.M. Shaheen, M. M. Selim, Effect of thermal treatment on physicochemical properties of pure and mixed manganese carbonate and basic copper carbonate, Thermochimca Acta, Vol. 322, 117-128, 1998.

[2] B. M. Reddy, E. P. Reddy, S. T. Srinivas, Dispersion and activity of molybdena-alumina catalysts prepared by impregnation and solid/solid wetting methods, Journal of Catalysis, Vol. 136, 50-58, 1992.

[3] F. Kapetien, J. Rodrigvez-Mirosol, J. A. Moulin, Heterogeneous catalytic decomposition of nitrous oxide, Applied Catalysis B, Vol. 9, 25-64, 1996.

[4] V. Mucka, Zeitschrift fur Physikalische Chemie-Wiesbaden, Vol. 270, No. 2, 246-256, 1989.

[5] N. R.E. Radwan, M. Mokhtar, G. A. El-Shobaky, Surface and catalytic properties of $\mathrm{CuO}$ and $\mathrm{Co}_{3} \mathrm{O}_{4}$ solids as influenced by treatment with $\mathrm{Co}^{2+}$ and $\mathrm{Cu}^{2+}$ species, Applied Catalysis A: General, Vol. 241, 77-90, 2003.

[6] L.G. Brynowicz, Identification of the thermal processes in the binary $\mathrm{Cu}(\mathrm{NO} 3) 2 \cdot 3 \mathrm{H}_{2} \mathrm{O}$ and $\mathrm{Cr}\left(\mathrm{NO}_{3}\right)_{3} \cdot 9 \mathrm{H}_{2} \mathrm{O}$ systems, Thermochimica Acta, Vol. 239, 181-199, 1994.

[7] Y. Yin, A. P. Alivisatos, Colloidal Nanocrystal Synthesis and the Organic-Inorganic Interface, Nature, Vol. 437, 664-670, 2005.

[8] S. C.N. Tang, I. M.C. Lo, Magnetic nanoparticles: Essential factors for sustainable environmental applications, Water Research, Vol. 47, 2613-2632, 2013 A review.

[9] D. J. Schiffrin, Capped Nanoparticles as Potential Electronic Components with Nanoscale Dimensions, MRS Bulletin, Vol. 26, 1015-1019, 2001.

[10] R. V. Kumar,Y. Mastai Y. Diamant, A. Gedanken. Sonochemical synthesis of amorphous $\mathrm{Cu}$ and nanocrystalline $\mathrm{Cu}_{2} \mathrm{O}$ embedded in a polyaniline matrix, Journal of Materials Chemistry, Vol. 11, 1209-1213, 2001.

[11] R.V. Kumar, R. Elgamiel,Y. Diamant, A. Gedanken, J. Norwig, Sonochemical preparation and characterization of nanocrystalline copper oxide embedded in poly(vinyl alcohol) and its effect on crystal growth of copper oxide, Langmuir, Vol. 17, 1406-1410, 2000 .

[12] A. A. Eliseev, A. V. Lukashin, A. A. Vertegel, L. I. Heifets LI, A. I. Zhirov, Y. D. Tretyakov, Complexes of $\mathrm{Cu}(\mathrm{II})$ with polyvinyl alcohol as precursors for the prepa-ration of
$\mathrm{CuO} / \mathrm{SiO}_{2}$ nanocomposites, Material Research Innovations, Vol. 3, 308-312, 2000.

[13] J. F. Xu, W. Ji, Z. X. Shen, S. H. Tang, X. R. Ye, D. Z. Jia, X.Q. Xin, Preparation and Characterization of $\mathrm{CuO}$ Nanocrystals, Journal of Solid State Chemistry, Vol. 147, 516-519, 1999.

[14] K. Borgohain, J. B. Singh, M. V. Rama Rao, T. Shripathi, S. Mahamuni, Quantum Size Effects in $\mathrm{CuO}$ Nanoparticles, Physical Review, Vol. B 61, 11093-11096, 2000.

[15] H. Saeidian, M. Abdoli, R. Salimi, One-pot synthesis of highly substituted pyrroles using nano copper oxide as an effective heterogeneous nanocatalyst, Comptes Rendus Chimie, (2013) Accepted Manuscript.

[16] A.Aimable, A. T. Puentes, P. Bowen, Synthesis of porous and nanostructured particles of $\mathrm{CuO}$ via copper oxalate route, Powder Technology, Vol. 208, 467-471, 2011.

[17] L. Carnes, T. Stipp, k. J. Jlabunde, J. Bonevich, Synthesis, characterization, and adsorption studies of nanocrystalline copper oxide and nickel oxide, Langmuir, Vol. 18, 1352-1359, 2002 .

[18] W. Wang, Y. Zhan, X. Wang, Y. Liu, C. Zheng, G. Wang, Synthesis and characterization of $\mathrm{CuO}$ nanowhiskers by a novel one-step, solid-state reaction in the presence of a nonionic surfactant, Materials Research Bulletin, Vol. 37, 1093-1100, 2002 .

[19] A. Sadana, J. R. Katzer, Involvement of free radicals in the aqueous-phase catalytic oxidation of phenol over copper oxide, Journal of Catalysis, Vol. 35, 140-152, 1974.

[20] H. Chen, G. Zhao, Y.Liu, Low-temperature solution synthesis of $\mathrm{CuO}$ nanorods with thin diameter, Materials Letters, Vol. 93, 60-63, 2013.

[21] J. M. Zamaro, N. C. Pérez, E. E. Miró, C. Casado, B. Seoane, C. Téllez, J. Coronas, HKUST-1 MOF: A matrix to synthesize $\mathrm{CuO}$ and $\mathrm{CuO}-\mathrm{CeO}_{2}$ nanoparticle catalysts for $\mathrm{CO}$ oxidation, Chemical Engineering Journal, Vols. 195-196, 180-187, 2012.

[22] D. Chen, G. Z. Shen, K. B. Tang, Y. T. Qian, Large-scale synthesis of $\mathrm{CuO}$ shuttle-like crystals via a convenient hydrothermal decomposition route, Journal of Crystal Growth, Vol. 254, 225-228, 2003.

[23] B. Liu, H. C. Zeng, Mesoscale organization of $\mathrm{CuO}$ nanoribbons: Formation of "dandelions, Journal of American Chemical Society, Vol. 126, 8124-8125, 2004.

[24] H. Wang, J. Z. Xu, J. J. Zhu, H-Y. Chen, Preparation of CuO nanoparticles by microwave irradiation, Journal of Crystal Growth, Vol. 244, 88-99, 2002.

[25] M. Wan, D. Jin, R. Feng, L. Si, M. Xia Gao, L. Yue, Pillow-shaped porous $\mathrm{CuO}$ as anode material for lithium-ion batteries, Inorganic Chemistry communications, Vol. 14, 38-41, 2011.

[26] Z. Jia, L. Yue, Y. Zheng, Z. Xu, The convenient preparation of porous $\mathrm{CuO}$ via copper oxalate precursor, Materials Research Bulletin, Vol. 43, 2434-2440, 2008.

[27] Y. Wang, J. Zhu, X. Yang, L. Lu, X. Wang, Preparation of $\mathrm{NiO}$ nanoparticles and their catalytic activity in the thermal decomposition of ammonium perchlorate, Thermochimica 
Acta, Vol. 437, 106-109, 2005.

[28] Y.R. Uhma, J.H. Park, W.W. Kima, C.H. Chob, C.K. Rhee, Magnetic properties of nano-size $\mathrm{Ni}$ synthesized by the pulsed wire evaporation (PWE) method, Materials Science Engineering B, Vol. 106, 224-227, 2004.

[29] S-H. Lin, F-R. Chen, J-J. Kai, Electrochromic properties of nano-composite nickel oxide film, Applied Surface Science, Vol. 254, 3357-3363, 2008.

[30] R. Cinnsealach, G. Boschloo, S.N. Rao, D. Fitzmaurice, Coloured electrochromic windows based on nanostructured $\mathrm{TiO} 2$ films modified by adsorbed redox chromophores, Solar Energy Materials and Solar Cells, Vol. 57, 107-125, 1999.

[31] D. H. Lee, K. Carroll, S. Calvin, S. Jin, Y. S. Meng, Conversion mechanism of nickel fluoride and NiO-doped nickel fluoride in Li ion batteries, Electrochimica Acta, Vol. 59, 213-221, 2012.

[32] H. Zhang, Y. Dong, W. Fang, Y. Lian, Effects of composite oxide supports on catalytic performance of Ni-based catalysts for CO methanation, Chinese Journal of Catalysis, Vol. 34, 330-335, 2013.

[33] C. S. Carney, C. J. Gump, A.W. Weimer, Rapid nickel oxalate thermal decomposition for producing fine porous nickel metal powders: Part 1: Synthesis, Materials Science Engineering A, Vol. 431, 1-12, 2006.

[34] Y. Wu, Y. He, T. Wu, W. Weng, H. Wo, Effect of synthesis method on the physical and catalytic property of nanosized NiO, Materials Letters, Vol. 61, 2679-2682, 2007.

[35] G-J. Li, X-X. Huang, Y. Shi, J-K. Guo, Preparation and characteristics of nanocrystalline $\mathrm{NiO}$ by organic solvent method, Materials Letters, Vol. 51, 325-330, 2001.

[36] P. Poizot, S. Laruelle, S. Grugeon, L. Dupont, J.-M. Tarascon, Nano-sized transition-metal oxides as negative-electrode materials for lithium-ion batteries, Nature, Vol. 407, 496-499, 2000.

[37] G. A. El-Shobaky, N. R. E. Radwan, M. S. El-Shall, A. M. Turky, H. M. A. Hassan, The role of method of preparation of $\mathrm{CuO}-\mathrm{NiO}$ system on its physicochemical surface and catalytic properties, Colloids and Surface A: Physicochemical Engineering and Aspects, Vol. 311, 161-169, 2007.

[38] G. A. El-Shobaky, N. R. E. Radwan, M. S. El-Shall, A. M. Turky, H. M.A. Hassan, Physicochemical, surface and catalyic properties of nanocrystalline $\mathrm{CuO}-\mathrm{NiO}$ system as being influenced by doping with $\mathrm{La}_{2} \mathrm{O}_{3}$, Colloids and Surface A: Physicochemical Engineering and Aspects, Vol. 345, 147-154, 2009

[39] G. A. El-Shobaky, N. R.E. Radwan, M. S. El-Shall, A. M. Turky, H. M. A. Hassan, Synthesis and characterization of pure and $\mathrm{ZrO}_{2}$-doped nanocrystalline $\mathrm{CuO}-\mathrm{NiO}$ system, Applied Surface Science, Vol. 254, 1651-1660, 2008.

[40] N. Bayal, P. Jeevanandam, Synthesis of $\mathrm{CuO} @ \mathrm{NiO}$ core-shell nanoparticles by homogeneous precipitation method, Journal of Alloys and Compounds, Vol. 537, 232-241, 2012.

[41] J-M. Huang, L-F. Xu, C. Qian, X-Z. Chen, N-alkylation of ethylenediamine with alcohols catalyzed by $\mathrm{CuO}-\mathrm{NiO} /$ $\gamma-\mathrm{Al}_{2} \mathrm{O}_{3}$ Chemical Papers, Vol. 66, 304-307, 2012 (SHORT COMMUNICATION).
[42] X. Chen, H. Luo, C. Qian, C. He. Reac. Kinet. Mech. Cat., Vol., 104, 163, 2011.

[43] X. Wang, J. Song, L. Gao, J. Jin, H. Zheng, Z. Zhang, Optical and electrochemical properties of nanosized $\mathrm{NiO}$ via thermal decomposition of nickel oxalate nanofibres, Nanotechnology, Vol. 16, 37-39, 2005.

[44] B. D. Cullity," Elements of x-ray diffraction", $3^{\text {rd }}$ Addison-Wesley, Reading, MA, 1967.

[45] B. A. Reguig, A. Khelil, L. Cattin, M. Morsli, J.C. Berne`de, Properties of $\mathrm{NiO}$ thin films deposited by intermittent spray pyrolysis process, Applied Surface Science, Vol. 253, 4330-4330, 2007.

[46] A. A. Said, E. A. Hassan and K. M. Abd El-Salam, Electrical conductivity and thermogravimetric studies of the thermal decomposition of doped cobalt carbonate, Surface Technology, Vol. 20, 123-130, 1983.

[47] J. Deren, J. Haber, A. Podgoreck and J. Burzyk, Physicochemical and catalytic properties of the system chromium oxides-oxygen-water, Journal of Catalysis, Vol. 2, $161-175,1963$.

[48] V. S. Nayak and J. B. Moffat, Comparison of the surface properties of the metal-oxygen cluster compounds, 12-tungstophosphoric acid and ammonium 12-tungstophosphate from the sorption of benzene, nitrogen and pyridin, Journal of Molecular Catalysis, Vol. 80, 75-93, 1989.

[49] X. Zhang, D. Zhang, X. Ni, H. Zheng, Optical and electrochemical properties of nanosized $\mathrm{CuO}$ via thermal decomposition of copper oxalate, Solid-State Electronics, Vol. $52,245-248,2008$

[50] M. M. M. Abd El-Wahab and R. M. Mahfouz, Gamma irradiation effects on the electrical conductivity behavior and thermal decomposition induction period in nickel oxalate, Thermochimica Acta, Vol. 274, 281-287, 1996.

[51] M. Salavati-Niasari, N. Mir, F. Davar, Synthesis and characterization of $\mathrm{NiO}$ nanoclusters via thermal decomposition, Polyhedron, Vol. 28, 1111-1114, 2009.

[52] A. M. Donia, Synthesis, identification and thermal analysis of coprecipitates of silver-(cobalt, nickel, copper and zinc) oxalate, Polyhedron, Vol. 16, 3013-3031, 1997.

[53] K. Nagase, Y. Zheng, Y. Kodama, J. Kakuta, Dynamic Study of the Oxidation State of Copper in the Course of Carbon Monoxide Oxidation over Powdered $\mathrm{CuO}$ and $\mathrm{Cu}_{2} \mathrm{O}$, Journal of Catalysis, Vol. 187, 123-130, 1999.

[54] D. Stoilova, V. Koleva, V. Vassileva, Infrared study of some synthetic phases of malachite $\left(\mathrm{Cu}_{2}(\mathrm{OH})_{2} \mathrm{CO}_{3}\right)$-hydrozincite $\left(\mathrm{Zn}_{5}(\mathrm{OH})_{6}\left(\mathrm{CO}_{3}\right)_{2}\right)$ series, Spectrochim. Acta A: Molecular and Biomolecular Spectroscopy, Vol. 58, 2051-2059, 2002.

[55] R. A. Nyguist, R. O. Kagel, "Infrared Spectra of Inorganic Compounds" Academic press, New Yourk and London (1971).

[56] N. M. Deraz, Characterization and catalytic performance of pure and $\mathrm{Li} 2 \mathrm{O}$-doped $\mathrm{CuO} / \mathrm{CeO}_{2}$ catalysts, Applied Surface Science, Vol. 255, 3884-3890, 2009.

[57] F. Davar, Z. Fereshteh, M. Salavati-Niasari, Nanoparticles Ni and NiO: Synthesis, characterization and magnetic properties, 
Journal of alloys and Compounds, Vol. 476, 797-801, 2009.

[58] M. Salavati-Niasari, F. Davar, Z. Fereshteh, Synthesis of nickel and nickel oxide nanoparticles via heat-treatment of simple octanoate precursor, Journal of alloys and Compounds, Vol. 494, 410-414, 2010.

[59] D. M. Fernandes, A. A. W. Hechenleitner, M. F. Silva, M. K. Lima, P. R. S. Bittencourt, R. Silva, M. A. C. Melo, E. A. G. Pineda, Preparation and characterization of $\mathrm{NiO}, \mathrm{Fe}_{2} \mathrm{O}_{3}$, $\mathrm{Ni}_{0.04} \mathrm{Zn}_{0.96} \mathrm{O}$ and $\mathrm{Fe}_{0.03} \mathrm{Zn}_{0.97} \mathrm{O}$ nanoparticles, Materials Chemistry and Physics, Vol. 118, 447-452, 2009.

[60] Z. Wei, H. Qiao, H. Yang, C. Zhang, X. Yan, Characterization of $\mathrm{NiO}$ nanoparticles by anodic arc plasma method, Journal of alloys and compounds, Vol. 479, 855-858, 2009.

[61] Z. Wang, Q. Liu, J. Yu, T. Wu, G. Wang, Surface structure and catalytic behavior of silica-supported copper catalysts prepared by impregnation and sol-gel methods, Applied Catalysis A: General, Vol. 239, 87-94, 2003.

[62] N. M. Deraz, Physicochemical, Surface, and Catalytic Properties of Pure and Ceria-Doped Manganese/Alumina Catalysts, Chinese Journal of Catalysis, Vol. 29, 687-695, 2008.

[63] N. M. Deraz, Effect of NiO content on structural, surface and catalytic characteristics of nano-crystalline $\mathrm{NiO} / \mathrm{CeO}_{2}$ system, Ceramics International, Vol. 38, 747-753, 2012.

[64] N. M. Deraz, Effects of heat treatment on physicochemical properties of cerium based nickel system, Journal of Analytical and Applied Pyrolysis, Vol. 95, 56-60, 2012.

[65] S.J.Brunauer, L. S.Deming, W. Deming, Teller, Journal of American Chemical Socitey, Vol. 62, 1723, 1940.

[66] J. H. de Boer, E. P. Everette, F. S. Stone, Eds, "The structure and properties of porous materials" Butterworths, (London), 68, 1985.

[67] Y. K. Jeong, G. M. Choi. J. Phys. Chem. Solis 57 (1996) 81.

[68] A. Bielanski, M. Nagbar, Adsorption species of oxygen on the surfaces of transition metal oxides, Journal of Catalysis, Vol. 25, 398-406, 1972.

[69] K. Kuchaynka, K. Klier, Collect. Czech. Chemistry Communication, Vol. 28, 148, 1963.

[70] R. P. Marcellini, R. E. Ranc, S. J. Teichner, "Actes du Congress International de Catalyse" $2^{\text {nd }}$ ed. (1960) 289.

[71] E. R. S. Winter, Adsorption upon pure and lithium-doped nickel oxide: I. Oxygen, Journal of Catalysis, Vol. 6, 35-49, 1966.

[72] P. Kofstad, " Non-Stoichiometry, Diffusion and electrical conductivity in binary metal oxides", John Wiley and Sons (N. Y) 246, 1972.

[73] G.A. El-Shobaky, I. F. Hewaidy, Th. El-Nabarawy, Sintering of non-stoichiometric $\mathrm{NiO}, \mathrm{CoO}$ and $\mathrm{Co} 3 \mathrm{O} 4$ catalysts, Surface Technology, Vol. 12, 309-315, 1981. 